УДК 616.98:578.828.6-085.37-06:616.24-002.5-02

DOI: $10.26435 /$ UC.V0I4(29).225

\author{
Е.В. Корж, Е.Г. Гуренко
}

ГОО ВПО «Донецкий национальный медицинский университет имени М. Горького», Донецк

\title{
ТУБЕРКУЛЕЗ КАК РЕЗУЛЬТАТ СИНДРОМА ВОССТАНОВЛЕНИЯ ИММУННОЙ СИСТЕМЫ ПОСЛЕ НАЧАЛА АНТИРЕТРОВИРУСНОЙ ТЕРАПИИ
}

На сегодняшний день стремительный рост количества больных ко-инфекцией туберкулез/ ВИЧ является одной из главных проблем современной эпидемии туберкулеза во всем мире. В связи с развитием у ВИЧ-инфицированных лиц тяжелых иммунодефицитных состояний туберкулез у них протекает злокачественно, с развитием генерализации туберкулезной инфекции и вовлечением в процесс многих внутренних органов. Внелегочные проявления туберкулеза заставляют больных обращаться к соответствующим узким специалистам, что затягивает сроки диагностики основного заболевания и ухудшает прогноз. Прогрессирующее угнетение иммунитета на фоне ВИЧ-инфицирования требует назначения антиретровирусной терапии (АРТ), которую, по современным представлениям, следует назначать независимо от содержания в крови CD4-лимфоцитов [1]. К сожалению, подавляющее большинство ВИЧ-инфицированных лиц не догадывается о своем состоянии и обращается за медицинской помощью только при появлении тяжелых расстройств здоровья, вызванных, как правило, оппортунистическими инфекциями (ОИ), которые сами по себе являются индикаторами глубокой иммуносупрессии. Начало АРТ у таких пациентов несет в себе высокий риск развития синдрома восстановления иммунной системы (СВИС) с проявлениями ранее не диагностированных, а потому и не пролеченных, инфекций, в том числе туберкулеза. Такое явление иногда называют «демаскирующий СВИС» или СВИС со «снятием маски» [2]. На сегодняшний день не существует четких критериев диагностики демаскирующего СВИС, поскольку его достаточно трудно дифференцировать с клиническими проявлениями ОИ у больных с выраженным угнетением иммунной системы $[3,4]$ На фоне иммунодефицита начальные симптомы активной туберкулезной инфекции зачастую остаются нераспознанными, поэтому тщательное обследование на туберкулез перед началом АРТ является залогом успешного лечения, сохранения и продления жизни больных.

\section{ЦЕЛЬИССЛЕДОВАНИЯ}

Оценить клинико-рентгенологические особенности и эффективность лечения туберкулеза, развившегося в результате СВИС после начала АРТ у ВИЧ-инфицированных пациентов.

\section{МАТЕРИАЛ И МЕТОДЫ}

Проведен ретроспективный анализ 24 медицинских карт стационарных больных коинфекцией туберкулез/ВИЧ, находившихся на лечении в Республиканской клинической туберкулезной больнице г. Донецка, у которых туберкулез развился после начала АРТ на догоспитальном этапе. Противовирусное лечение назначалось врачами-инфекционистами центров СПИДа и кабинетов доверия по месту жительства, перед началом лечения проводили объективный осмотр, рентгенографию органов грудной клетки (ОГК), определяли содержание CD4лимоцитов в крови. В исследование включали случаи активного туберкулеза, возникшего в течение первых трех месяцев приема антиретровирусных препаратов, что позволяет рассматривать его, как проявление СВИС [5]. Полученные данные представляли в виде медианы, качественные признаки - в виде частоты проявления [6].

\section{РЕЗУЛЬТАТЫ И ОБСУЖДЕНИЕ}

Изучение анамнестических данных показало, что перед назначением АРТ у всех пациентов имелось выраженное угнетение иммунной системы - количество CD4 колебалось от 1 кл/ мкл до 271 кл/мкл в абсолютных значениях, и от 0,3\% до 17,6\% в процентном соотношении. Медианы соответствующих показателей составляли 35 кл/мкл и 4,7\%. У 19 человек $(79,0 \%)$ уровень Т-хелперов был ниже 100 кл/мкл. Известно, что лица с тяжелым иммунодефицитом состав-

(C) Е.В. Корж, Е.Г. Гуренко, 2018

(c) Университетская Клиника, 2018 
ляют особую группу риска развития СВИС, поэтому перед назначением противовирусных препаратов такие пациенты должны быть обследованы особенно тщательно, в том числе и для исключения активного туберкулеза. Вместе с тем, анализ медицинской документации позволил сделать вывод о недостаточной настороженности врачей общей лечебной сети в плане развития вышеуказанных осложнений. Так, на момент начала АРТ не имели никаких жалоб только 7 человек (29,2\%), тогда как 13 (54,2\%) жаловались на постоянный или периодический субфебрилитет, в том числе 5 - с эпизодами лихорадки до 38,0-39,0 С, слабость беспокоила 12 человек $(50,0 \%) \%, 8$ пациентов $(33,3 \%)$ отмечали наличие кашля с небольшим количеством слизистой мокроты, 4 (16,7\%) - снижение массы тела, у 2 лиц $(8,3 \%)$ имелась неврологическая симптоматика (головная боль, слабость в конечностях, нарушение речи). Таким образом, подавляющее большинство больных имело выраженные в той или иной степени признаки расстройства здоровья, что, несомненно, требовало дополнительных усилий для выяснения причины их появления. Из сопутствующих ОИ у 19 лиц (79,2\%) выявляли кандидоз полости рта, по одному случаю диагностировали саркому Капоши, токсоплазмоз головного мозга и цитомегаловирусный ретинит.

Изучение рентгенограмм, выполненных на догоспитальном этапе перед началом АРТ, показало, что нормальная картина органов грудной клетки определялась у 11 человек (45,8\%), более чем у половины лиц на рентгенограммах имелись те или иные изменения, из которых наиболее часто отмечали патологию легочного рисунка - 13 случаев (54,2\%). Изменения легочного рисунка носили характер мелкоячеистой «сетки», более выраженной в верхних отделах. Данные нарушения мы расценивали как проявление гиперергического состояния сосудистого русла легких, возникающего, очевидно, в результате как местных тканевых реакций, так и периодической циркуляции туберкулезных микобактерий в крови, что становится возможным при угнетении защитных иммунных реакций. При более детальном рассмотрении у 3 человек на фоне усиленного легочного рисунка в верхних отделах периваскулярно можно было заметить единичные малоинтенсивные мелкоочаговые тени, у 6 больных - умеренное расширение тени корней с нечетким полициклическим контуром, что указывало на возможное поражение внутригрудных лимфатических узлов (ВГЛУ).

Наличие вышеуказанных жалоб и изменений на рентгенограммах является, на наш взгляд, основанием для отсрочки АРТ и проведения дополнительного обследования, как минимум компьютерной томографии ОГК и органов брюшной полости. Клинический опыт позволяет сделать вывод, что в таких ситуациях активный туберкулезный процесс у пациента скорее есть, чем нет, поэтому существует высокий риск его манифестации после начала АРТ. Мы считаем, что при невозможности уточнить природу имеющихся нарушений противовирусные препараты следует назначать под прикрытием противотуберкулезной химиотерапии, а ее схемы, сроки и продолжительность нуждаются в дополнительном изучении для разработки четких рекомендаций.

APT на догоспитальном этапе назначали по традиционным трехкомпонентным схемам для наивных пациентов, включающим 2 нуктеотидных/нуклеозидных и один ненуклеозидный ингибитора обратной транскриптазы. Первые симптомы активного туберкулеза появлялись в сроки от 3 до 60 дней после начала АРТ, медиана 19 дней. Все больные жаловались на слабость и повышение температуры тела, в том числе у 20 человек $(83,3 \%)$ лихорадка достигала фебрильных цифр. При поступлении в отделение неврологические нарушения (головная боль, расстройства сознания, тошнота, рвота, слабость в конечностях, менингеальные знаки) определялись у 9 лиц (37,5\%), в дальнейшем после дополнительного обследования им был выставлен диагноз туберкулезного менингита. Туберкулез диагностировали впервые у 16 больных (66,7\%), у остальных пациентов развился рецидив заболевания.

Туберкулез, развившийся вследствие СВИС, характеризовался тяжелым течением с частым развитием гематогенного распространения туберкулезной инфекции: диагноз генерализованного туберкулеза прижизненно был установлен у 17 пациентов (70,8\%), в легких выявляли преимущественно диссеминированные процессы с наличием деструкций у трети пациентов (см. табл.). Обращало на себя внимание вовлечение в процесс лимфоидной системы: поражение лимфатических узлов (внутригрудных и/или периферических) имело место у 23 больных (95,8\%). Бактериовыделение методами микроскопии мазка и посева выявляли у 9 больных (37,5\%). У 8 человек (33,3\%) были получены положительные результаты культурального исследования мокроты, проведение теста лекарственной чувствительности в половине случаев выявило наличие множественной лекарственной устойчивости (у 3 человек с впервые диагностированным туберкулезом и у одного с рецидивом).

За стационарный период лечения умерло 
Характеристика туберкулезного процесса в обследованной группе пациентов

Таблица.

\begin{tabular}{lcc}
\hline \multicolumn{1}{c}{ Показатели } & Число случаев & $\%$ \\
\hline \hline Диссеминация в легких & 16 & 66,7 \\
\hline Инфильтраты в легких & 8 & 33,3 \\
\hline Деструкции легких & 8 & 33,3 \\
\hline Поражение ВГлу & 17 & 70,8 \\
\hline Поражение периферических лимфоузлов & 5 & 20,8 \\
\hline Экссудативный плеврит & 6 & 25,0 \\
\hline Менингит & 9 & 37,5 \\
\hline Поражение лимфоузлов брюшной полости & 1 & 4,2 \\
\hline Генерализованный туберкулез & 17 & 70,8 \\
\hline
\end{tabular}

14 человек, госпитальная летальность составила $58,3 \%$. На аутопсии у всех умерших обнаруживали острый милиарный туберкулез множественных локализаций, в том числе с поражением селезенки, печени, почек. В половине случаев смерть наступила в результате прогрессирования туберкулеза с нарастанием интоксикации и развитием полиорганной недостаточности, и 7 человек погибли вследствие туберкулезного менингита с отеком головного мозга и вклинением миндалин мозжечка в большое затылочное отверстие. Всего из 9 больных СВИСассоциированным туберкулезным менингитом умерло семеро $(77,8 \%)$, что указывает на злокачественное течение данной патологии и согласуется с ранее опубликованными выводами [7]. Высокий удельный вес пациентов с туберкулезом нервной системы объясняется специализацией отделения, где выполнялись исследования, на лечении такой категории больных, поэтому в данном исследовании не может отражать частоту развития этого осложнения в структуре всех клинических форм СВИС-ассоциированного туберкулеза. Из оставшихся пациентов 8 человек (33,3\%) успешно закончили стационарный этап противотуберкулезной химиотерапии и были выписаны для продолжения лечения в амбулаторных условиях, двое больных переведены в другие учреждения.

\section{В Ы В $О$ д Ы}

1. Туберкулез, развивающийся в результате СВИС, возникает у ВИЧ-инфицированных лиц с глубокой иммуносупрессией при назначении АРТ без антимикобактериальных препаратов, характеризуется быстрым развитием (медиана - 19 дней), склонностью к генерализации (до $70,8 \%$ случаев) и неблагоприятным прогнозом с высокой госпитальной летальностью, достигающей 58,3\%. Особенно злокачественным течением отличается СВИС-ассоциированный туберкулез нервной системы, при котором летальность достигает $77,8 \%$.

2. Более половины пациентов $(54,2 \%)$ перед началом АРТ отмечали повышение температуры тела и слабость, у такого же количества лиц на рентгенограммах ОГК определялось усиление легочного рисунка, у каждого четвертого - увеличение внутригрудных лимфатических узлов. Наличие указанных симптомов является основанием для отсрочки АРТ и более детального обследования пациентов. При невозможности верифицировать причину патологии представляется целесообразным начинать прием противовирусных препаратов под прикрытием противотуберкулезной химиотерапии, однако ее схема и продолжительность нуждаются в изучении и четкой регламентации. 


\section{Е.В. Корж, Е.Г. Гуренко}

ГОО ВПО «Донецкий национальный медицинский университет имени М. Горького», Донецк

\section{ТУБЕРКУЛЕЗ КАК РЕЗУЛЬТАТ СИНДРОМА ВОССТАНОВЛЕНИЯ ИММУННОЙ СИСТЕМЫ ПОСЛЕ НАЧАЛА АНТИРЕТРОВИРУСНОЙ ТЕРАПИИ}

Начало антиретровирусной терапии у ВИЧинфицированных лиц несет в себе высокий риск развития синдрома восстановления иммунной системы с проявлением ранее не диагностированных инфекций, в том числе туберкулеза.

Целью исследования было оценить клиникорентгенологические особенности и эффективность лечения туберкулеза, развившегося в результате СВИС после начала АРТ у ВИЧ-инфицированных пациентов.

Материал и методы. Изучены 24 медицинские карты стационарных больных ко-инфекцией туберкулез/ВИЧ, находившихся на лечении в Республиканской клинической туберкулезной больнице г. Донецка, у которых туберкулез развился в течение первых трех месяцев после начала антиретровирусной терапии. На догоспитальном этапе всем пациентам перед началом противовирусного лечения проводили объективный осмотр, рентгенографию органов грудной клетки, определяли содержание CD4-лимоцитов крови.

Результаты и обсуждение. Перед началом антиретровирусной терапии медианы содержания CD4 в крови пациентов составляли 35 кл/мкл и 4,7\%, не имели жалоб 7 человек (29,2\%)\%, 13 (54,2\%) отмечали повышение температуры тела, 12 (50,0\%) - слабость, 8 (33,3\%) - кашель с мокротой, 4 (16,7\%) - снижение массы тела, и у 2 лиц $(8,3 \%)$ имелась неврологическая симптоматика. Рентгенологически нормальная картина органов грудной клетки определялась у 11 больных (45,8\%), у 13 (54,2\%) имелось усиление легочного рисунка, у 6 (25,0\%) - увеличение внутригрудных лимфатических узлов. Первые симптомы туберкуле- за появлялись в сроки от 3 до 60 дней, медиана - 19 дней, все больные отмечали лихорадку и слабость, у 9 (37,5\%) наблюдались признаки туберкулезного менингита, у 17 (70,8\%) - генерализованного туберкулеза. За стационарный период лечения умерло 14 человек (58,3\%). Из 9 больных туберкулезным менингитом погибло семеро (77,8\%). Успешно закончили стационарный этап противотуберкулезной химиотерапии и были выписаны для продолжения лечения в амбулаторных условиях 8 человек (33,3\%).

Выводы. Туберкулез, развивающийся в результате синдрома восстановления иммунной системы, возникает у ВИЧ-инфицированных лиц с глубокой иммуносупрессией при назначении антиретровирусной терапии без антимикобактериальных препаратов, характеризуется быстрым развитием, склонностью к генерализации и неблагоприятным прогнозом. Особо злокачественным течением отличается туберкулезный менингит, при котором летальность достигает $77,8 \%$. У $54,2 \%$ больных перед началом противовирусного лечения отмечались лихорадка, у такого же количества - усиление легочного рисунка, у 25,0\% - увеличение внутригрудных лимфатических узлов. Наличие указанных симптомов является основанием для отсрочки антиретровирусной терапии и детального обследования пациентов. При невозможности верифицировать причину патологии целесообразно начинать противовирусное лечение под прикрытием противотуберкулезной химиотерапии, однако ее схема и продолжительность нуждаются в четкой регламентации.

Ключевые слова: туберкулез, синдром восстановления иммунной системы.

\section{E.V. Korzh, E.G. Gurenko}

\section{SEI HPE «M. Gorky Donetsk National Medical University», Donetsk}

\section{TUBERCULOSIS AS THE RESULT OF THE IMMUNE RECONSTITUTION INFLAMMATORY SYNDROME AFTER INITIATION OF ANTIRETROVIRAL THERAPY}

Initiation of antiretroviral therapy in HIV-infected individuals carries a high risk of immune reconstitution inflammatory syndrome with manifestation of previously not diagnosed infections, including tuberculosis.

The aim of the study was to estimate the clinical and radiological features and effectiveness of treatment of tuberculosis that developed as a result of immune reconstitution inflammatory syndrome after the initiation ART in HIV-infected patients.

Material and methods. 24 medical records of inpatients with co-infection tuberculosis/HIV who were treated in the Donetsk Republican Clinical Tuberculosis Hospital were analyzed. All patients developed tuberculosis within the first three months after initiation of antiretroviral therapy. At the pre-hospital stage, all patients before starting antiviral treatment were examined (objective examination, chest X-ray, content of CD4 in the blood).

Results and discussion. Before initiation of antiretro- viral therapy, the medians of CD4 content were 35 cells/ $\mu \mathrm{L}$ and $4.7 \%, 7$ persons $(29.2 \%)$ had no complaints, 13 (54.2\%) complained of fiver, 12 (50.0\%) of weakness, 8 (33.3\%) of cough with a sputum, 4 (16.7\%) of weight loss, and 2 persons $(8.3 \%)$ had neurological symptoms. X-ray normal picture of the chest was determined in 11 persons $(45,8 \%), 13$ persons $(54.2 \%)$ had an intensification of the pulmonary marking, $6(25,0 \%)$ - increased intrathoracic lymph nodes. The first symptoms of tuberculosis appeared within 3 to 60 days, the median was 19 days, all patients noted fiver, 9 persons (37.5\%) had signs of tuberculous meningitis, 17 (70.8\%) had generalized tuberculosis. During a stationary period of treatment, 14 people died (58.3\%). From 9 patients with tuberculous meningitis, seven persons (77.8\%) died. 8 people (33.3\%) successfully completed a stationary anti-tuberculosis chemotherapy and were discharged to continue treatment at home. 
Conclusions. Tuberculosis, which develops as a result of the immune reconstitution inflammatory syndrome, occurs in HIV-infected individuals with severe immunodeficiency when prescribing antiretroviral therapy without anti-tuberculosis drugs, characterized by generalized forms in $70.8 \%$ and high hospital mortality, reaching $58,3 \%$. Especially malignant course has tuberculous meningitis, lethality reaches $77.8 \%$. Before starting antiviral treatment in $54.2 \%$ of patients fever and intensification of the pulmonary marking was noted, in $25.0 \%$
- an increased intrathoracic lymph nodes. The presence of complaints and X-ray changes is the basis for delaying antiretroviral therapy and additional examination of patients. If it is impossible to verify the cause of these disorders, it is advisable to start antiviral therapy under the cover of anti-tuberculosis chemotherapy, however, its schemes and duration need clear regulation.

Key words: tuberculosis, immune reconstitution inflammatory syndrome.

\section{ЛИТЕРАТУРА}

1. WHO Consolidated Guidelines on the Use of Antiretroviral Drugs for Treating and Preventing HIV Infection: recommendations for a public health approach implications for the African region. 2017 WHO | Regional Office for Africa. Available from: https://www.afro.who.int/publications/ who-consolidated-guidelines-use-antiretroviral-drugstreating-and-preventing-hiv)

2. Surendra K. Sharma, Manish Soneja. HIV \& immune reconstitution inflammatory syndrome (IRIS). Indian J Med Res. 2011; 134(6): 866-877. doi:10.4103/0971-5916.92632

3. Haddow L.J., Easterbrook P.J., Mosam A., Khanyile N.G., Parboosing R., Moodley P., Moosa M.Y. Defining immune reconstitution inflammatory syndrome: evaluation of expert opinion versus 2 case definitions in a South African cohort. Clin Infect Dis. 2009; 49 (9): 1424-1432. doi:10.1086/630208

4. Lawn S.D., Meintjes G. Pathogenesis and prevention of immune reconstitution disease during antiretroviral therapy. Expert Rev Anti Infect Ther. 2011; 9 (4): 415-430. doi:10.1586/eri.11.21]

5. Ossibi Ibara R.B., Okemba Okombi F.H., Niama R.F., Bemba E.L.P., Doukanga T., Boumandouki J.P.S., Ngoyi Ontsira E.N. Epidemiological Features and Associated Factors of Pulmonary Tuberculosis with Positive Microscopy in the Infectious Diseases Unit at the CHU of Brazzaville. J Lung Pulm Respir Res 2017; 4(5): 00143. doi:10.15406/ jlprr.2017.04.00143

6. Лях Ю.Е., Гурьянов В.Г., Хоменко В.Н., Панченко О.А. Основы компьютерной биостатистики. Анализ информации в биологии, медицине и фармации статистическим пакетом MedStat. Донецк; 2006. 214.

7. Корж Е.В., Тлустова Т.В.. Влияние антиретровирусной терапии на лечение туберкулезного менингоэнцефалита у ВИЧ-инфицированных пациентов. Проблемы здоровья и экологии. 2014; 39 (1): 63-67.

\section{REFERENCES}

1. WHO Consolidated Guidelines on the Use of Antiretroviral Drugs for Treating and Preventing HIV Infection: recommendations for a public health approach implications for the African region. 2017 WHO | Regional Office for Africa. Available from: https://www.afro.who.int/publications/ who-consolidated-guidelines-use-antiretroviral-drugstreating-and-preventing-hiv)

2. Surendra K. Sharma, Manish Soneja. HIV \& immune reconstitution inflammatory syndrome (IRIS). Indian J Med Res. 2011; 134(6): 866-877. doi:10.4103/0971-5916.92632

3. Haddow L.J., Easterbrook P.J., Mosam A., Khanyile N.G., Parboosing R., Moodley P., Moosa M.Y. Defining immune reconstitution inflammatory syndrome: evaluation of expert opinion versus 2 case definitions in a South African cohort. Clin Infect Dis. 2009; 49 (9): 1424-1432. doi:10.1086/630208

4. Lawn S.D., Meintjes G. Pathogenesis and prevention of immune reconstitution disease during antiretroviral therapy. Expert Rev Anti Infect Ther. 2011; 9 (4): 415-430. doi:10.1586/eri.11.21]

5. Ossibi Ibara R.B., Okemba Okombi F.H., Niama R.F., Bemba E.L.P., Doukanga T., Boumandouki J.P.S., Ngoyi Ontsira E.N. Epidemiological Features and Associated Factors of Pulmonary Tuberculosis with Positive Microscopy in the Infectious Diseases Unit at the CHU of Brazzaville. J Lung Pulm Respir Res 2017; 4(5): 00143. doi:10.15406/ jlprr.2017.04.00143

6. Lyakh Yu.E., Gur'yanov V.G., Khomenko V.N., Panchenko O.A. Osnovy komp'yuternoi biostatistiki. Analiz informatsii v biologii, meditsine i farmatsii statisticheskim paketom MedStat. Donetsk; 2006. 214 (in Russian).

7. Korzh E.V., Tlustova T.V.. Vliyanie antiretrovirusnoi terapii na lechenie tuberkuleznogo meningoentsefalita u VIChinfitsirovannykh patsientov. Problemy zdorov'ya i ekologii. 2014; 39 (1): 63-67 (in Russian). 